\title{
“O2O+TDT”Model: Design of Integrated Teaching System for Teaching and Practical Training in Market Research Course Based on Informatization
}

\section{Qingjiao Chen}

National Demonstration Center for Experimental Economics and Management Education (Guangxi University of Finance and Economics), Daxuexi Road NO.189, Nanning, Guangxi, China

aemail:chillies_2006@163.com

Keywords: Market Research; Teaching and Practice Course system; Informatization; O2O; TDT

\begin{abstract}
Based on the essence of market research course, information technology is applied to the teaching process to construct an integrated teaching system, namely the"O2O + TDT" model. Case study method is used for the key point analysis of the course system construction. In the selection of cases, theoretical sampling method is adopted and Guangxi University of Finance and Economics, which is known as the school-enterprise alliance was selected as the case analysis object. This research aims to contribute to the reform of market-based teaching and training system.
\end{abstract}

\section{Introduction}

With the development of information technology, the teaching reform of Market Research course has become one of the research focuses especially in China. As shown in Figure1, there is a rapid growing trend in the number of research papers in this field. However, there are still many shortcomings in current teaching system [1][2],which can be summarized as follows:(1)Theoretical teaching has attracted much of the attention while the practice part is more or less being neglected.(2) Teaching methods and teaching tools are monotonous, therefore, students are lack of participation enthusiasm.(3)Course assessment is too simple to truly evaluate student's comprehensive ability. In response to these problems, many scholars have given useful suggestions for curriculum reform. For example, Tao Zhou discussed the teaching reform model of Market Research based on knowledge sharing, emphasizing the teaching concept of "student-centered"[2]. Huijuan Zhou discussed the design of market research courses from a flipping classroom perspective[1].The above scholars have put forward suggestions for market research teaching reform from different perspectives, but they haven't proposed any solutions to enhance the practicality of the course. As a practical and applied course, Market Research has high requirements for students' comprehensive ability, however, the existing practical training teaching is mere formality which fails to reflect its practical significance. Jie Tang, Yingdou Liu, and Zhenzhen Wang discussed the design of a teaching system from the perspective of teaching and training integration, which is of great significance in solving the disconnect between theory and practice. However, the corresponding application of advanced teaching technology and curriculum assessment and evaluation have not been analyzed. With reference to Jie Tang et al.'s research, this article uses a new Internet-based teaching technology, classroom design method, and experimental operation software to explore the integrated curriculum design of teaching and training in Market Research course[3][4]. In addition, this paper sheds light on the transformation of learning outcome.

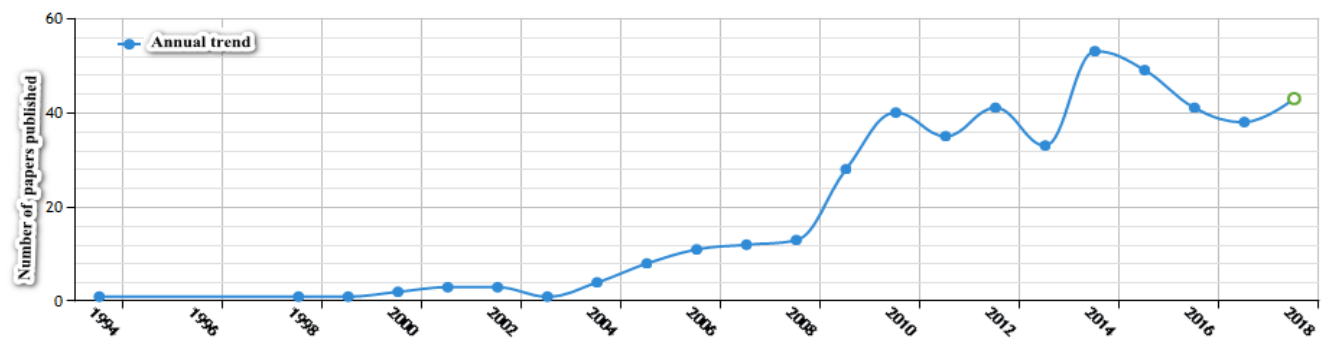

Fig 1 Research trend of Market Research Courses in China 


\section{Methods and Design Principles}

\subsection{Methods.}

The article uses case study and logic deduction. In the selection of cases, theoretical sampling method is adopted and Guangxi University of Finance and Economics which is known as the school-enterprise alliance was selected as the case analysis object.

\subsection{Design Principles.}

Based on the nature of Market Research, the integrated Teaching and Training Course is designed abiding by the following principles: Firstly, theoretical guiding which refers to the delivery of a completed knowledge system to students. Secondly, application of advanced technologies, for example, the internet technique, Rain classroom and others which can enhance teaching efficiency. Thirdly, the interaction among teaching, learning and doing. Currently, the three links are disconnect, resulting in students' weak knowledge base and adding difficulty to achieve good outcome in class. Finally, outcome transformation. The outcomes of the course are not merely for course assessment, but also can be translated into entries or reports guiding the practice of companies.

\section{3. "O2O + TDT" Teaching System Based on Informatization}

\subsection{Information-based teaching environment.}

Introduce a training platform support system and build an information-based teaching environment. Informatization teaching is to use modern information technology and digital resources to provide students with high-quality information learning conditions according to the guidance of modern teaching philosophy and optimize teaching activities throughout the teaching process under the circumstance of educational informatization[5][6].The introduction of practical training platform is a fundamental way to realize teaching informatization. The development of marketing comprehensive simulation software has become more mature. By introducing marketing comprehensive simulation software, teaching effect can be improved greatly.

\subsection{0 platform.}

As shown in Figure 2, O2O is online to offline, which is to use the internet and other advanced techniques to achieve flipped classroom education. Compared with traditional teaching model, the flipped classroom requires students to acquire knowledge through teaching videos uploaded by their teachers before the class. In the classroom, teachers and students are supposed to interact through answering of questions, group discussions and other forms so as to assist students' mastery of knowledge. This form is reverse to the traditional classroom where teachers lecture in class and students finish their homework and group discussion after class.

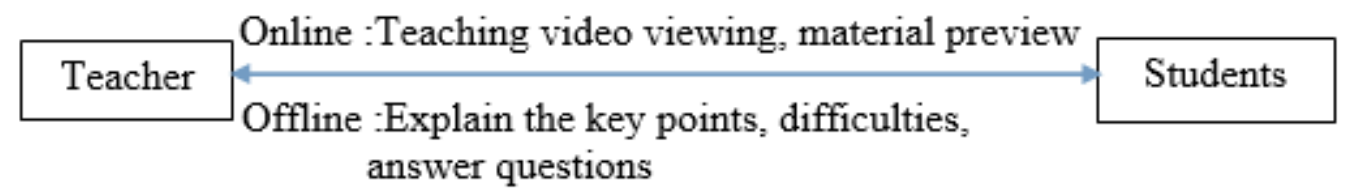

Fig 2 O2O Teaching model

\subsection{TDT system.}

As shown in Figure 3, TDT is short for “Teaching-Doing-Transformation”. It is an Internet-based teaching and training curriculum system. Its core elements consist of three interconnected links: knowledge teaching, student operation and transformation of learning outcome. First of all, each teaching link corresponds to a student operation link as Internet-based information technology can closely link teaching and operation together. Secondly, the transformation of learning outcome is a high-level incentive for students to operate. Compared with course assessment, the transformation of learning outcome can better stimulate students' active involvement in the practical training session. Curriculum transformation is the fundamental driving force of high-quality practical training results. 
Third, Result Transformation re-feeds Teaching. The detailed explanation of each part of the TCT system is as follows.

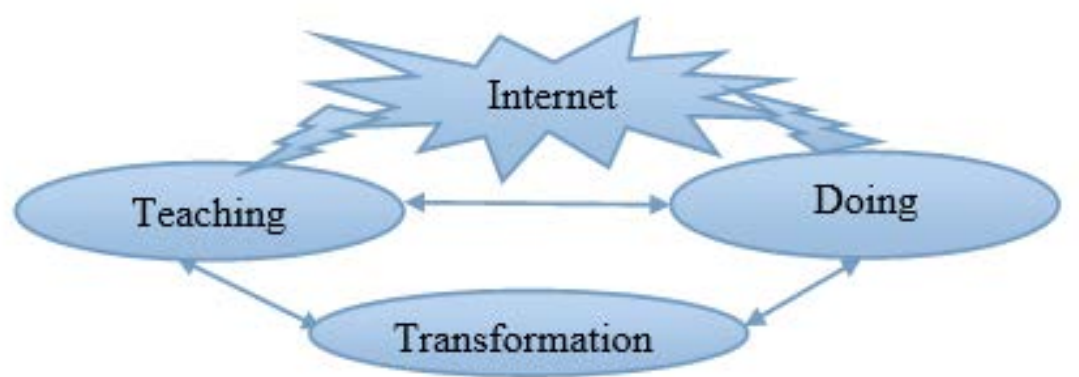

Fig3 TDT course model

\subsection{Teaching.}

In the overall teaching design, project teaching method is adopted. The most prominent feature of project teaching method is "taking the project as the main line, the teacher as the guide, and the student as the main body", which changes the passive teaching model of "teachers talking and students listening” by introducing a new teaching model featuring students' active participation, independent collaboration, and exploration and innovation[7]. According to the production process of market research report, course explanation usually adopts thematic method, and the content is often divided into the following sections: (1) Topic selection; (2) Literature review; (3) Research plan design; (4) Design of data collection tools; (5) Data collection; (6) Data analysis; (7) Investigation report writing; (8) Road show training. In order to enhance the enthusiasm of students and the fairness of evaluation, project teaching method is underpinned by a 360-degree assessment method. In addition to self-evaluation, each team member also receives evaluations from teachers, team leaders, and other team members which are of different weights. By scoring, each student's performance in the project is calculated.

\subsection{Doing.}

The actual operation of students is the core part of the course, and it is also an important method to test the learning effect. Thematic knowledge must be matched with repeated operations. Whenever a project team completes a specific task, the teacher must offer corresponding evaluation and counseling, point out their improper operation and ask students modify it. This process should repeat for two or three times.

\subsection{Transformation of learning outcome.}

Transform survey reports into competition or consultation reports. In current teaching, the transformation of learning outcome is often ignored. Teachers and students only use the survey reports for assessment, which leads to the students' low involvement in writing their survey reports. Taking the transformation of learning outcome as the ultimate goal will stimulate students' enthusiasm for learning and creation. At present, there are three common ways to transform learning outcome: First, participate in competitions and take them as an entries; Second, use them to guide innovation and entrepreneurship projects; Thirdly, provide them to third parties as advisory reports. Of the three approaches, the threshold of the first one is the lowest.

\section{Case study}

By taking Guangxi University of Finance and Economics as an example, this paper designs a course system of market investigation and teaching, and analyzes the model of "O2O+TDT".

\subsection{Case brief.}

Guangxi University of Finance and Economics is an application-oriented undergraduate 
University in western China. The market research course is employed by School of Business Administration which aims at students who are majored in marketing and business administration.

\subsection{Key points in designing the teaching system.}

The dominant resources of this university lie in the combined resources of the school itself and enterprises. In the setting of the teaching system, the advantages of the school should be fully utilized to make the most of the "O2O + TDT" model. The design of the main link is shown in Figure 4.

First, make use of the information technology training platform. At present, this school has already had a national first-class marketing comprehensive laboratory, and installed market research simulation software which can provide teaching simulation experiments from the investigation questions to the investigation structure analysis. This school has rich resources in school-enterprise cooperation, therefore, perfect training base can be established through school-enterprise cooperation channels.

Second, build “O2O” platform: Internet + Rain classroom. Rain classroom is a mini flipped classroom software with low technical barriers. Compared with MOOC and other forms of flipped classroom, the production of Rain classroom is low in cost, short in time, and easy to achieve, thus, Rain classroom is suitable for schools of various sizes to achieve flipped classroom education.

Third, practice the TDT system. (1) Teaching tasks are jointly performed by teachers and business personnel. Teachers mainly deal with theoretical explanations and solutions, while business personnel are responsible for the guidance in the selection of designs and practical operation. (2) Diversification of student operating scenes. Students' operating environment includes three scenes: laboratory, enterprise and society. (3) Diversification of the transformation paths of learning outcome.

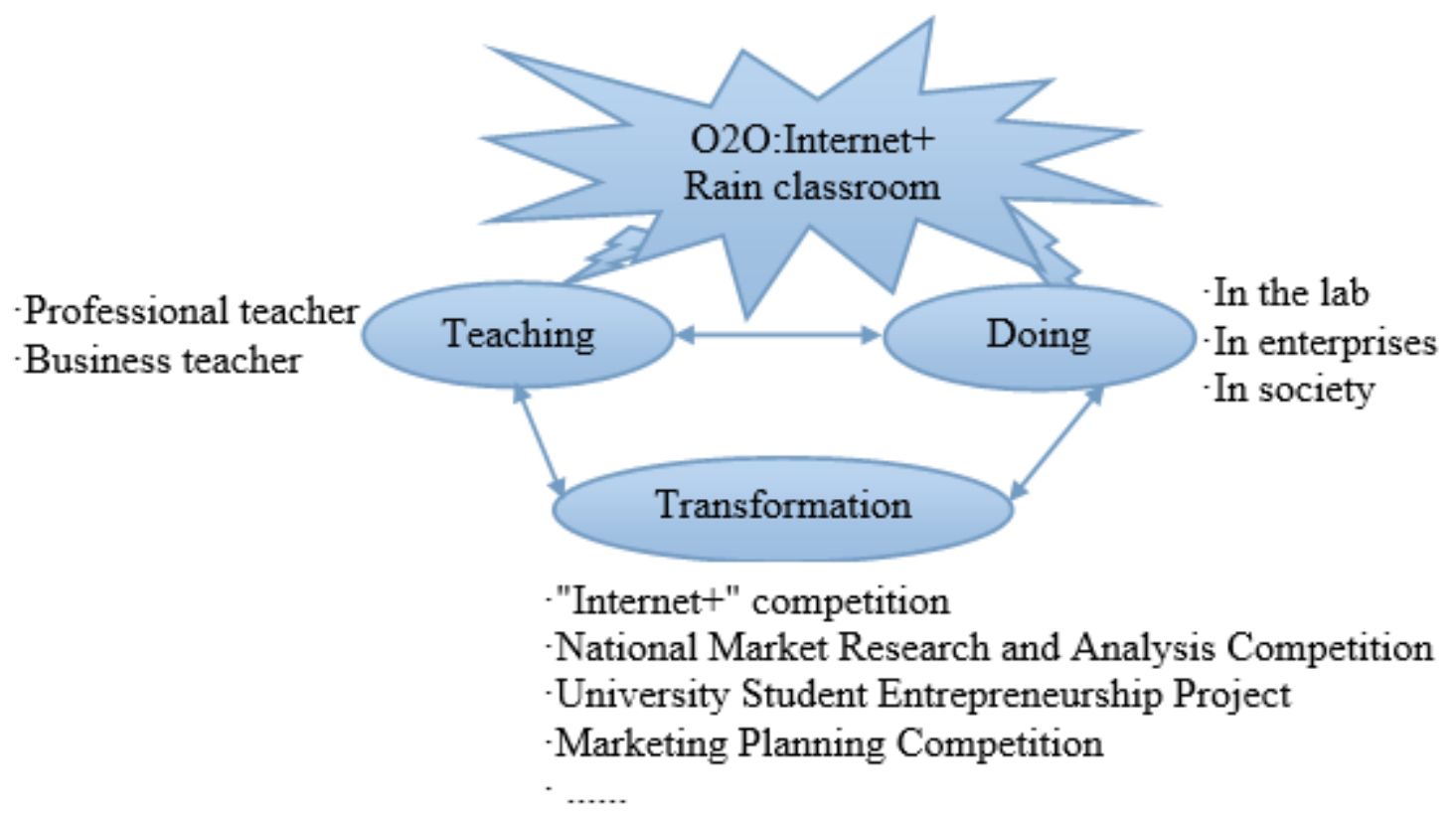

Fig 4 Design of "O2O+TDT" in the Market Research Course of Guangxi University of Finance and Economics

\section{Conclusion}

Market research is a very practical course, which should adhere to the principle of integration of teaching and practical training. The main conclusions of this paper are as follows: (1) The application of information technology is of great significance to improve teaching efficiency. The construction of informatization teaching environment, the establishment of $\mathrm{O} 2 \mathrm{O}$ teaching platform, and the adoption of simulation teaching software are the key elements of informatization teaching. (2) In the course of teaching, project teaching method can be used to set up a TDT system so that teaching, practice and transformation of learning results will be able to supplement each other. 


\section{References}

[1] Huijuan Zhou.The course design of market investigation and analysis based on flipped classroom model .Journal of Jincheng Vocational and Technical College,2015,8(01):42-45.

[2] Tao Zhou .Reform of "Market Investigation and Forecasting" Teaching Model Based on Knowledge Creation. Journal of Shandong University of Technology (Social Science Edition), 2016, 32(05):100-105.

[3] Jie Tang, Yingdou Liu, Zhenzhen Wang .Integrative Innovation of Practical Teaching of Investigation Curriculum: Taking Two-step Innovation of Marketing Investigation and Prediction Curriculum as an Example.Journal of Jing de zhen University.2017, 32(2):78-83.

[4] Stern, Bruce L., and LP Douglas Tseng. "Do academics and practitioners agree on what and how to teach the undergraduate marketing research course?" Journal of Marketing Education 24.3 (2002): 225-232.

[5] Horton, John J., David G. Rand, and Richard J. Zeckhauser. "The online laboratory: Conducting experiments in a real labor market." Experimental economics 14.3 (2011): 399-425.

[6] Xiangdong Chang, Lixin Zhao. Design of Informatization Teaching for College Specialty Courses. China Management Informatization,2011,14(5):74-75.

[7] Gang Li .Research on the Application of Project Teaching Method in the Course of "Market Investigation and Forecasting".Chinese market, 2015(06):43-44+64. 